\title{
Método e Forma da Exposição na Ciência da Lógica de Hegel
}

\author{
Diogo Ferrer ${ }^{1}$
}

\begin{abstract}
RESUMO: O artigo questiona a afirmação de Hegel de que a sua filosofia obedece a um método, denominado "dialética", buscando esclarecer o conceito, os procedimentos e o significado filosófico daquilo a que Hegel chama "método". Após um breve estudo do método dialético em obras anteriores, onde ainda não alcançou a sua maturidade, o estudo em questão centra-se na dialética lógica segundo a Ciência da Lógica (1812, 1813, 1816). O artigo estuda o significado da "contradição" como operador metodológico, e o motivo por que o método dialético é caracterizado de diferentes maneiras em diversas passagens da obra. Enfim, mostra-se que, ao invés de um instrumento avesso ao conceber e de uma arte subjetiva, o método hegeliano produz procedimentos e resultados suficientemente regulares.
\end{abstract}

Palavras-chave: Hegel; Método; Dialética; Ciência da Lógica; Contradição

\begin{abstract}
The article questions the claim of Hegel that his philosophy follows a method called "dialectic", seeking to clarify the concept, procedures and philosophical significance of what Hegel called "method". After a brief study of the dialectical method in previous works, which have not yet reached its maturity, the study in question focuses on the dialectical logic according to the Science of Logic $(1812,1813,1816)$. The article examines the meaning of the "contradiction" as methodological operator and why the dialectical method is characterized in different ways in different passages of the work. Finally, it is that, instead of an instrument inside the design and a subjective art, the Hegelian method produces sufficiently regular procedures and results.
\end{abstract}

Key-words: Hegel; Method; Dialectic; Science of Logic; Contradiction

"For this reason, the hand of the logician should not appear in his system. Having stipulated the rules for how the signs which appear in his system are to be combined, he should withdraw and allow the operation of the signs to speak for him."

H. O. Mounce

A afirmação de Hegel de que a sua filosofia obedece a um método, denominado "dialética", merece um questionamento a diferentes níveis. É legítimo questionar então a existência de algo como um método na filosofia de $\mathrm{Hegel}^{2}$. Não só é questionável se se trata de um instrumento teórico que mereça realmente o nome de "método", ou se não se trata antes de uma arte irreproduzível ${ }^{3}$ e, portanto, sem caráter

\footnotetext{
${ }^{1}$ Universidade de Coimbra, Portugal

${ }^{2}$ Cf. e.g. W. Maker, Philosophy without Foundations. Rethinking Hegel (State University of New York Press, Albany, 1994. 99).

${ }^{3}$ Cf. Hegel, Wissenschaft der Logik. Die Lehre vom Begriff (1816), ed. H.-J. Gawoll, Felix Meiner, Hamburg, 1994, 291 [=1816]. Parte das concepções aqui apresentadas são reformulações de exposições
} 
metódico. Não parece tão-pouco claro se possui um caráter suficientemente homogêneo e regular que cabe a um método ${ }^{4}$, ou se há um ou diversos métodos em diferentes épocas do desenvolvimento do pensamento de Hegel e, ainda, se se trata de um instrumento de pensamento suscetível de algum tipo de expressão formal ou algoritmização ${ }^{5}$.

Tentarei neste estudo um esclarecimento acerca do conceito, do conjunto de procedimentos e do significado filosófico daquilo a que Hegel chama "método", mantendo as questões apresentadas como orientação mais geral. A concepção mais clara do seu "método" só parece ser alcançada por Hegel no final do período de Iena, e o seu desenvolvimento plenamente realizado aparece apenas a partir da Ciência da Lógica. Centrarei o estudo do método, nestes termos, na dialética lógica, com exclusão, para além de uma breve introdução, das obras anteriores ao primeiro volume da Ciência da Lógica, a Doutrina do Ser, de 1812.

\section{Antecedentes}

As referências a um método dialético são relativamente frequentes no texto de Hegel, desde as primeiras obras de Iena até ao projeto tardio de reedição da Fenomenologia do Espírito em 1831, passando pela Ciência da Lógica, as diversas edições da Enciclopédia ou as Linhas Fundamentais da Filosofia do Direito. Tais referências não são, no entanto, nem tão esclarecedoras nem tão unívocas que permitissem uma leitura fácil do problema ${ }^{6}$.

presentes na minha obra D. Ferrer, Lógica e Realidade em Hegel. A Ciência da Lógica e o Problema da Fundamentação do Sistema (Centro de Filosofia, Lisboa, 2006). Aí também se encontra uma bibliografia mais pormenorizada.

${ }^{4}$ Cf. R. Schäfer, Die Dialektik und ihre besonderen Formen in Hegels Logik. Entwicklungsgeschichtliche und systematische Untersuchungen (Felix Meiner, Hamburg, 2001).

5 Recorde-se o estudo de M. Kosok, "The Formalization of Hegel's Dialectical Logic. Its Formal Structure, Logical Interpretation and Intuitive Foundation", in A Macintyre (ed.), Hegel. A Collection of Critical Essays (University of Notre Dame Press, Notre Dame / London, 1972, 237-287)e, ou mais recentemente Wandschneider para quem não se trata de um método algoritmizável (Grundzüge einer Theorie der Dialektik. Rekonstruktion und Revision dialektischer Kategorien-Entwicklung in Hegels 'Wissenschaft der Logik', Stuttgart, Klett-Cota, 1995, 184), sendo no entanto reconstruível como uma teoria rigorosa de antinomias.

${ }^{6}$ Numa primeira aproximação é e.g. correta a opinião de R. D. Winfield, de que "Hegel fail[s] to supply in advance anything that could count as a unitary doctrine of method. Instead he offers episodic reflections [...] whose compatibility [...] is far from obvious" (R. D. Winfield, From Concept to 
Uma brevíssima análise de alguns dos antecedentes histórico-conceptuais da dialética conforme se encontra nos escritos da maturidade de Hegel, mostra que a generalidade dos seus temas e motivos estão já presentes em escritos anteriores, faltando principalmente o seu arranjo sistemático. Os textos escritos durante os anos de Iena mostram que a definição da forma final e do correto significado do método não resultaram de um processo simples, e que aquilo que possa surgir eventualmente como um perfil relativamente coerente de processos e resultados teve de atravessar diversos momentos de desenvolvimento, explicitação e esboços prévios, que nos aparecem por vezes como hesitantes ou até mesmo confusos. Deverá poder compreender-se assim, por outro lado, que foi o encaixe das diversas peças metodológicas no seu lugar conceptualmente adequado que permitiu a Hegel a elaboração de um sistema exposto em formas completas como as da Ciência da Lógica de 1812-1816 ou da Enciclopédia das Ciências Filosóficas, que poderá ser encarada em parte como simples esboço e sumário, em parte como uma exposição diferente do sistema.

Não há dúvida de que a chamada dialética de Hegel tem antecedentes na Doutrina da Ciência de Fichte, que encara já o procedimento por meio de "antíteses" como construtivo de conteúdo conceptual determinado, e não só destrutivo, como era o caso na dialética kantiana. O procedimento, digamos 'protodialético' de Fichte, a que este autor não dá nenhum nome especial, está explicitamente descrito, em 1794/95, nos seus Fundamentos da Doutrina da Ciência. Esta descrição programática descreve de modo bastante fiel, acrescente-se, o desenvolvimento que Fichte efetivamente dá aos seus princípios.

\footnotetext{
“Temos por conseguinte, em cada proposição, de partir da indicação de opostos que devem ser unificados. [...] Temos, por isso, no eu e no não-eu ligados pela síntese suprema, e na medida em que são unificados por ela, de procurar notas características opostas que restem, e de as ligar por um novo fundamento de relação, o qual tem de estar novamente contido no fundamento supremo de todos os fundamentos de relação: nos opostos ligados por esta primeira síntese temos então, novamente, de buscar novos
}

Objectivity. Thinking Through Hegel's Subjctive Logic, Ashgate, Hants / Burlington, 2006, 19). Uma interpretação mais atenta permitirá encontrar, pelo contrário, algo de conceitualmente comum entre estas diferentes reflexões. 
opostos, unificá-los por um novo fundamento de relação, contido no anteriormente derivado, [e assim por diante]"”.

No entanto, esta formulação precursora tem tanto de esclarecedor quanto de insuficiente para a compreensão da dialética de Hegel. Por um lado, implica diretamente a tese hegeliana fundamental de que a partir da oposição, que Fichte desenvolve como sendo de tipo contraditório, entre "princípios" opostos, geram-se, como resultado, sínteses que constituem o conteúdo conceptual da ciência lógica - que, no caso de Fichte, mas em parte também para Hegel, consiste numa analítica e dialética transcendentais simultâneas. Por outro lado, toda a aparelhagem conceptual mencionada no excerto citado de Fichte, de "princípios" ou "proposições" (Sätze), "eu” e "não-eu", bem como a necessidade de uma "busca" dos opostos será em geral recusada por Hegel.

Em contraste com o caráter lógico e metodologicamente esclarecido desta protodialética lógica, que encontramos explícito no projeto de Fichte, encontra-se, nos textos de juventude de Hegel, um ideal de reconciliação entre opostos ao nível não lógico mas vivido, moral e religioso ${ }^{8}$. Depressa este ideal de reconciliação que tinha nascido, nos textos de juventude, a partir de oposições vividas e morais, se desenvolve, a partir da viragem de 1801, numa filosofia sistemática. Encontra-se a abrir a Differenzschrift uma espécie de teoria da dialética, sem aparência diretamente lógica ou metodológica, mas definindo a tarefa da filosofia como a da solução de oposições que se dão sob a forma de dualidades filosóficas tradicionais. Assim, "a cisão é a fonte da necessidade da filosofia" ${ }^{\prime 9}$ e, consequentemente, dados opostos como finito e infinito, espírito e matéria, alma e corpo ou crença e razão, segundo Hegel "o único interesse da razão é superar tais opostos, tornados fixos" $"$.

\footnotetext{
7"Wir müssen demnach bey jedem Satze von Aufzeigung Entgegengesetzter, welche vereinigt werden sollen, ausgehen. [...] Wir haben demnach in den durch sie [sc. die höchste Synthesis] verbundenen Ich und Nicht-Ich, insofern sie durch dieselbe verbunden sind, übriggebliebene entgegengesetzte Merkmahle aufzusuchen, und sie durch einen neuen Beziehungsgrund, der wieder in dem höchsten aller Beziehungsgründe enthalten seyn muß, zu verbinden: in den durch diese erste Synthesis verbundenen Entgegengesetzen abermals neue Entgegengesetzte zu suchen, diese durch einen neuen, in dem erst abgeleiteten enthaltenen Beziehungsgrund zu verbinden [u.s.w...]." (Fichte, Gesamtausgabe, Friedrich Frommann, Stuttgart-Bad Cannstatt, 1965, I/2, 275)

${ }^{8}$ Hegel, Werke (ed. E. Moldenhauer \& K. Michel, Suhrkamp, Frankfurt a. M., 1970, 1992. [= Werke]) Bd. 1, 354, 355, 394.

9 "Entzweiung ist der Quell des Bedürfnisses der Philosophie" (Werke, Bd. 2, 20).

10 "[S]olche festgewordene Gegensätze aufzuheben, ist das einzige Interesse der Vernunft" (Werke, Bd. 2, 21).
} 
A consciência lógica deste projeto filosófico encontra-se enunciada por Hegel, ainda a fazer os seus inícios na filosofia sistemática, em 1801, na sua primeira Tese de Habilitação: "contradictio est regula veri, non contradictio falsi" primeira formulação, contra-intuitiva e paradoxal, Hegel dá o mote para todo o desenvolvimento posterior do método, reafirmado no ano seguinte, por exemplo, no artigo sobre o ceticismo ${ }^{12}$, onde o método aparece registado, explicitamente denominado como dialética e dominado em muitos dos seus aspectos fundamentais, nos esboços de sistema, em especial na Lógica de Iena, de 1805. A ordenação das disciplinas proposta nesta fase do pensamento de Hegel impede ainda, entretanto, o pleno desenvolvimento do método.

A organização definitiva das disciplinas filosóficas, e a consequente ideia mais clara do método das oposições, ainda demorará entretanto alguns anos, nomeadamente pelo menos até à Fenomenologia do Espírito. A análise do texto desta obra mostra, porém, por vezes um uso do método das oposições menos regular do que seria de esperar para um procedimento estritamente científico ${ }^{13}$, conforme reivindicado por Hegel. Tais dificuldades parecem derivar do próprio projeto e composição da obra, e encontram-se expressas nas irregularidades da prática dialética aí presente. Permanece então nalguma obscuridade a estrutura da obra, apesar do significado filosófico fundamental de muitas das suas passagens e argumentações de pormenor ou de médio alcance. São conhecidas as razões históricas e editoriais que ditaram uma tal indefinição ${ }^{14}$.

As oposições e contradições são aqui, de fato, buscadas muitas vezes por meio de procedimentos não explicitados e nem sempre tem o mesmo significado e implicações, deixando-se reconduzir, por exemplo, a oposições entre contrários, à intervenção de instâncias críticas e de motivos variados, apresentação de contrafatuais e

\footnotetext{
${ }^{11}$ Werke, Bd. 2, 533.

${ }^{12}$ Werke, Bd. 2, 229.

${ }^{13}$ Acerca desta questão v. o meu estudo Ferrer, "Observing Reason in Hegel's Phenomenology of Spirit", in E. Pires (ed.) Still Reading Hegel's Phenomenology of Spirit (Imprensa da Universidade, Coimbra, 3748 [no prelo]).

${ }^{14}$ Cf. O. Pöggeler, Hegels Idee einer Phänomenologie des Geistes, Freiburg / München, 1993.
} 
outros. A análise desta ausência de regularidade não será, contudo, o objeto deste estudo $^{15}$.

Entretanto, se nem a ordem disciplinar nem a configuração metodológica do sistema da filosofia estão ainda claramente estabelecida nestes esboços e primeiras exposições sistemáticas, a generalidade dos seus motivos e da sua concepção já estão explícitos. Assim, (1) os escritos de juventude apresentam o ideal filosófico da resolução de dualismos e oposições fixos através de uma filosofia da vida e do espírito; (2) os escritos de Iena introduzem temas como a interpretação lógica destas dualidades como contradições; (3) a necessidade da contradição para a definição do "verdadeiro"; (4) a incorporação dos resultados do ceticismo na filosofia; (5) a necessidade de uma definição 'objetiva' ou imanente da contradição ${ }^{16}$; até, por fim, (6) a Fenomenologia poder tematizar largamente a noção de negatividade ${ }^{17}$; bem como (7) a relação da refutação com o desenvolvimento de um processo dialético de derivação de figuras do pensar $^{18}$, ou categorias; e (8) a ligação entre forma e conteúdo permitida pela lógica dialética $^{19}$. E assim, só a partir do momento em que estes vários elementos caem, por assim dizer, nos seus lugares próprios, com a unificação disciplinar entre lógica e metafísica, e o método pode operar de modo tanto quanto possível homogêneo, objetivo e apreendendo uma totalidade sistemática de determinações, é que o sistema pôde adquirir a sua forma madura. De certo modo, a forma sistemática resulta da correta colocação das pedras conceptuais do método. Esta ligação entre método e sistema encontra-se explícita no curso da Fenomenologia do Espírito $^{20}$, a partir do qual a estrutura lógico-dialética do pensar hegeliano se encontrará, por assim dizer, estabilizada. Todos os elementos enunciados serão integrados no método dialético da maturidade de Hegel, de forma coerente e sistemática.

A cientificidade da filosofia tem duas condições centrais. Por um lado, o seu caráter metódico, assegurado pela dialética, por outro, o fato de constituir um sistema. $\mathrm{O}$ método não pode, por conseguinte, ser isolado do desenvolvimento sistemático da

\footnotetext{
${ }^{15}$ Cf. Ferrer, op.cit.

${ }^{16}$ Este tópico fundamental é perfeitamente claro na passagem da Lógica à Metafísica de Iena. (Jenaer Systementwürfe II. Logik, Metaphysik, Naturphilosophie, Felix Meiner, Hamburg, 1982, 117, 135).

${ }^{17}$ Hegel, Phänomenologie des Geistes (ed. Bonsiepen, Felix Meiner, Hamburg, 1988 [= 1807]), 14, 42.

${ }^{18} 1807,18$.

${ }^{19}$ Winfield (op. cit., 20), apresenta uma enumeração aparentada de seis "general features" do método: 1) unidade de forma e contudo; 2) autodesenvolvimento; 3) negação determinada; 4) circularidade; 5) analiticidade e sinteticidade simultâneas; 6) o método é resultado final do desenvolvimento.

${ }^{20} 1807,35$.
} 
filosofia, e a ligação conceptual estreita entre os dois é, do mesmo modo, um dos pontos capitais que permitem o desenvolvimento da filosofia especulativa como Ciência da Lógica. Assim, se é verdade que o método se apresenta como definição de máxima generalidade para a cientificidade de qualquer procedimento, com o mesmo nível de generalidade, contudo, pode encontrar-se a forma sistemática da filosofia. Por um lado, "é claro que não podem valer como científicas quaisquer exposições que não sigam o curso deste método" 21 . Por outro, "um filosofar sem sistema não pode ser nada de científico" ${ }^{22}$. A complementaridade conceptual destas determinações é defendida por Hegel, na medida em que é o próprio "método [que] se amplia [...] em sistema",23. As condições e consequências desta ligação serão explicitados e analisadas nas partes seguintes deste estudo.

\section{A Ciência da Lógica entre classificação e derivação de categorias}

As determinações essenciais do método podem ser entendidas como respostas às exigências levantadas pela Ciência da Lógica como ciência autônoma do pensar e primeira disciplina do sistema. Uma primeira análise imediata da forma da sua apresentação mostra que nela confluem dois registos epistemológicos, ambos tradicionais, mas jamais antes reunidos de modo comparável. A exposição da Ciência da Lógica reúne numa só figura epistemológica dois significados distintos do termo "sistema".

Em primeiro lugar, "sistema" designa uma ordem classificativa ${ }^{24}$. A forma geral da exposição da Lógica hegeliana faz-nos percorrer, por um lado, uma classificação, quase sempre tripartida, de "determinações" ou conteúdos categoriais do pensar. Encontram-se, assim, três grandes grupos de conteúdos segundo três grandes partes, ou "doutrinas": o ser, a essência e o conceito. Cada uma destas grandes seções funciona como um título classificatório para novas tripartições em famílias e gêneros.

\footnotetext{
21 "Es ist klar, daß keine Darstellungen für wissenschaftlich gelten können, welche nicht den Gang dieser Methode gehen" (Hegel, Wissenschaft der Logik, Die Lehre vom Sein (1832), ed. H.-J. Gawoll, Felix Meiner, Hamburg, 1990 [= 1832], 39).

22 "Ein Philosophieren ohne System kann nichts Wissenschaftliches sein" (Werke, Bd. 8 [= 1830], § 14). Cf. tb. $1807,6,18$.

23 "Die Methode selbst erweitert sich [...] zu einem System" (1816, 300). Cf. tb. 1807, 35.

24 E. Oeser, System, Klassifikation und Evolution. Historische Analyse und Rekonstruktion der wissenschaftlichstheoretischen Grundlagen der Biologie, Wilhelm Braumüller, Wien, 1996. 19ss.
} 
Assim, por exemplo, na Doutrina do Ser encontramos "qualidade", "quantidade" e "medida", cada uma das quais novamente dividida em tripartições, segundo um regime que se repete em toda a obra. É claramente visado um sistema, pretensamente completo, de conteúdos científicos, dispostos por maior ou menor proximidade e distância conceptuais. A proximidade e distância é definida, em parte, por graus de complexidade ou "concretude" - nos termos de Hegel - e, em parte, também segundo o método de descoberta, ou antes, de geração das determinações respectivas. Assim, (1) aqueles conteúdos que são descobertos por um método de "devir de determinações" deverão ser tratados sob a rubrica do "Ser"; (2) aqueles que são descobertos ou "produzidos" - por "aparecerem um no outro", deverão ser incluídos na segunda rubrica, a da "essência"; e, finalmente, (3) aqueles que resultam de um "desenvolvimento" deverão ser integrados no terceiro domínio, o da "Doutrina do Conceito" 25 . Trata-se, assim, de uma taxinomia de categorias diferenciadas por grupos de proximidade e distância.

Uma questão prévia é a da definição do tipo de materiais ou conteúdos que devem ser classificados pela lógica. Hegel assume que se trata de determinações do pensar, categorias ou "pensamentos objetivos", o que se poderá entender como "significações" em sentido lato e objetivo ${ }^{26}$. O conteúdo é, assim, o próprio pensar, e a lógica deve ser a ciência do pensar nas suas determinações mais gerais. Uma segunda questão prévia é onde se encontram e devem buscar estes conteúdos a ordenar e expor cientificamente. Tratando-se de "pensamentos objetivos" ou, dito talvez mais claramente, de pensamentos objetivados, eles encontram-se disponíveis, segundo Hegel, por um lado na linguagem, por outro, na história da filosofia ${ }^{27}$. A lógica deverá, por conseguinte, tratar de determinações tanto linguísticas, quanto lógicas em sentido tradicional, o que incluía uma doutrina do conceito, da proposição e do silogismo, e ainda outras provenientes da ontologia e das metafísicas especiais da tradição filosófica.

\footnotetext{
${ }^{25}$ Cf. Schäffer, op.cit.

${ }^{26}$ Dificilmente poderíamos encontrar aqui melhor comentário do que a definição husserliana do termo "categorias": "se falamos então de categorias lógicas, só se pode tratar de puras especificações que se separam a priori no interior deste gênero 'significação', ou de formas correlativamente co-pertencentes da objetividade categorialmente apreendida enquanto tal." ("Sprechen wir also im Plural von logischen Kategorien, so kann es sich nur um reine Artungen handeln, die sich a priori innerhalb dieser Gattung Bedeutung scheiden, oder um korrelativ zugehörige Formen der kategorial gefaßten Gegenständlichkeit als solcher.") (Husserl, Logischen Untersuchungen, II, 1, Tübingen, 1968, 95)

27 Acerca da presença das determinações do pensar na linguagem cf. 1832, 9-10, 19. Acerca da sua presença na História da Filosofia, v. 1830, §§ 13-14.
} 
Esta disponibilidade empírica de um reservatório, por assim dizer, de determinações do pensar objetivadas é uma condição necessária para a exposição da Ciência da Lógica ${ }^{28}$. Mas não constitui de modo nenhum condição suficiente, na medida em que o conceito filosófico requer que a própria exposição da ligação, sequência e organização dos materiais obedeça a uma fundamentação não ocasional e empírica, mas pensada também ela logicamente ou posta ao nível do conceito, i.e., concebida. Todavia, este trabalho de classificação e definição de categorias ou conteúdos abstratos do pensar, retirados em geral da história da metafísica e da lógica ou até das ciências empíricas e das metafísicas especiais, não esgota de modo nenhum a reivindicação científica de Hegel. Nomeadamente, os contéudos a classificar não devem ser retirados empiricamente da história - natural ou social - mas efetivamente deduzidos como necessários e os únicos necessários. Esta exigência é, na verdade, a da fundamentação da própria lógica. Supõe-se que a única fundamentação adequada para a lógica é uma fundamentação também ela lógica, i.e., feita sobre os mesmos princípios que prescreve aos materiais que organiza e sistematiza. Qualquer outra fundamentação, histórica, empírica ou outra, seria uma metabasis eis allo genos que faria da lógica um produto, ou resultado de uma outra ciência pressuposta como seu fundamento. Mas a reivindicação de Hegel é que todas estas relações epistemológicas que permitem falar de ciência em geral, ou de questões como fundamentação ou pressuposição, por exemplo, são o conteúdo específico da Ciência da Lógica. A fim de efetivamente expor o seu conteúdo próprio, a Lógica não pode, em consequência, pressupor nenhuma outra ciência. Naturalmente, está aqui implicada a já referida unidade entre forma e conteúdo característica da lógica dialética. Ou seja, se deve ser ciência das determinações do pensar, ela não pode distinguir entre pensamento objetivo ou objetivado a expor como seu conteúdo, e algum pensamento subjetivo, dotado de outras categorias, de métodos e de razões diversas daquelas que são justamente o conteúdo e objeto desta ciência, pensamento subjetivo que se apresentasse como uma "forma" exterior ao "conteúdo" a ser exposto ${ }^{29}$. Justamente por isso, a lógica dialética recusa o método se por este se

\footnotetext{
${ }^{28}$ Cf. a questão sobre o espírito subjetivo, para o qual e pelo qual as determinações lógicas devem ser pensadas, in Fulda, Hegel (Beck, München, 2003, 126). Sobra a presença do conteúdo na história da filosofia, tb. K. de Boer, "The Dissolving Force of the Concept: Hegel's Ontological Logic", in The Review of Metaphysics, 57 (2004), 187-822, 797, 821

${ }^{29}$ Uma consulta ao capítulo da Ciência da Lógica sobre a relação entre "forma e conteúdo" permite encontrar explicitamente tematizadas as razões por que e condições sob as quais forma e conteúdo não são determinações separadas, mas implicam-se mutuamente. V. Hegel, Wissenschaft der Logik. Die Lehre vom Wesen (1813) (ed. H.-J. Gawoll, Felix Meiner, Hamburg, 1992 [= 1813]), 77ss.
} 
entende um instrumento previamente disponível que deva ser "aplicado",30 a um material estranho. As falhas lógicas de uma tal concepção tornar-se-ão claras ao longo deste estudo, pelo que seria desnecessário criticá-la em especial neste ponto.

Entretanto, se para satisfazer a exigência de fundamentação conceptual e pensante, novamente se buscar no reservatório de formas já historicamente reconhecidas do pensar, encontra-se (1) o conceito modal de "necessidade", com o qual Hegel exprime justamente aquilo que é a exigência científica da exposição das determinações do pensar. Trata-se de um "agir necessário da razão",31. Mas encontra-se igualmente (2) a disciplina tradicional da lógica que expõe as condições pelas quais umas determinações - conceitos e juízos - podem ser retiradas de outras com necessidade. Hegel encontra nesta disciplina uma resposta geral a esta exigência teórica, não obstante a "necessidade de começar de novo com esta ciência"32. Contudo, ainda um outro elemento disponível será integrado na Ciência da Lógica, a saber, (3) o da erística e do ceticismo. A razão da inclusão da refutação e do ceticismo é a necessidade de um pensar fundamentado, ou seja, a exigência científica de que as determinações não sejam simplesmente admitidas umas ao lado das outras, mas que haja efetiva fundamentação de cada uma delas. $\mathrm{O}$ ceticismo, que as põe sistematicamente em causa pelo raciocínio erístico é, naturalmente um bom candidato a pedra de toque da fundamentação de todas e de cada uma das determinações do pensar.

A ciência lógica deve traduzir-se, por conseguinte, numa fundamentação simultaneamente lógica, necessária e refutativa dos seus conteúdos. Esta ligação necessária entre os conteúdos conduz então ao segundo dos modelos herdados de "sistema". Num segundo sentido herdado por Hegel, designadamente da metafísica prékantiana, o termo "sistema" designa também uma filosofia fundada numa cadeia lógicodedutiva $^{33}$. Cada determinação é gerada, com necessidade lógica e argumentativa, a partir da imediatamente anterior, o que parece corresponder à exigência conceptual de encontrar um concepção necessária e de derivação lógica das determinações entre si. Este segundo modo de conceber um "sistema" científico reflete o fato de que não é

\footnotetext{
${ }^{30}$ Sobre a "aplicação" cf. 1816, 269.

31 "Kant hat die Dialektik höher gestellt - und diese Seite gehört unter die größtern seiner Verdienste -, indem er [...] sie als ein notwendiges Tun der Vernunft darstellte" $(1832,41)$. V. tb. 1832, 19.

32 "Die Notwendigkeit, mit dieser Wissenschaft wieder einmal von vorne anzufangen ..." $(1832,6)$.

${ }^{33} \mathrm{Ch}$. Krijnen, Philosophie als System. Prinzipientheoretische Untersuchngen zum Systemgedanken bei Hegel, im Neukantismus und in der Gegenwartsphilosophie, Königshausen \& Neumann, Würzburg, 2008, 16.
} 
suficiente classificar conteúdos sem tomar em consideração se se trata de uma ordenação objetiva, que responde a uma necessidade interna dos próprios conteúdos classificados, ou se se trata de um dos denominados sistemas "artificiais", nos quais a classificação deriva do arbítrio do sujeito classificador ${ }^{34}$.

Estas duas figuras epistemológicas do "sistema", a classificativa e a dedutiva são normalmente entendidas como separadas e estanques, isto é, a filosofia que procede sistematicamente no sentido de dedutivamente, segundo a forma das metafísicas précríticas, não fornece propriamente árvores classificativas, ao passo que os sistemas classificativos não pretendem assumir uma força de necessidade lógica. Como disciplina do "pensar" de cariz estático e classificativo, a lógica deve expor os conteúdos do pensar que lhe são próprios segundo uma classificação apropriada. Na sua vertente "dinâmica", a lógica deduz determinações umas a partir das outras numa forma linear, por sucessivas refutações.

A exposição destas duas formas epistemológicas diversas numa figura unificada só é possível sob certas condições, a que exposição da Ciência da Lógica obedece. Assim, se devem corresponder a uma efetiva ordenação "natural" ou “objetiva" dos conteúdos, as classes não podem ser definidas arbitrariamente, mas segundo notas características comuns que são reproduzidas, ou retornam em diferentes momentos da derivação. Estas notas características mais gerais são, a saber, a imediatez, a mediação e o retorno à imediatez. A questão é largamente tematizada no principal texto metodológico, no final da Ciência da Lógica ${ }^{35}$. Assim, em geral, este triplete retorna a todos os níveis de desenvolvimento da exposição e define, por exemplo, as três grandes divisões da obra, Ser, Essência e Conceito bem como, dentro de cada uma destas divisões, novamente outras subdivisões e assim sucessivamente. O problema de reunir uma exposição classificativa com uma exposição de algum modo dedutiva e linear é resolvido por meio do estabelecimento de paralelismos e circularidades na exposição. A exposição retorna, de modo circular, ao início, apresentando sempre novos

\footnotetext{
${ }^{34}$ Em Hegel, v. n. 41 infra. Acerca dos sistemas "artificiais", cf. E. Oeser, op.cit., 26ss.

${ }^{35}$ Cf. 1816, 288ss. Embora o número de fases possa ser também visto de outro modo, para maior simplicidade podem considerar-se três.
} 
círculos, segundo a conhecida descrição de Hegel, do sistema como "círculo de círculos" $"$.

A necessidade conceptual e lógica que deve ser atribuída aos lugares classificativos dos conteúdos lógicos a tratar traduz-se na derivação, ou "dedução imanente $^{, 37}$ de umas determinações a partir das outras. Esta derivação ocorre então, conforme exposto, segundo círculos sucessivos que se podem entender ainda, além disto, como ordens de paralelismo ${ }^{38}$. Os momentos imediatos são paralelos mais ou menos distantes entre si, bem como os momentos de mediação e de retorno ao imediato. Pode observar-se, assim, por exemplo, a primeira grande divisão (Lógica do Ser) determinada pela primeira categoria do primeiro ciclo dialético (“ser”), a segunda grande divisão (Lógica da Essência) determinada pela segunda categoria deste primeiro ciclo ("nada"39), e a terceira grande divisão (Lógica do Conceito), finalmente, pela terceira categoria do primeiro ciclo dialético ("devir" ${ }^{40}$ ). Note-se que, como é conhecido, os conteúdos anteriores não são abandonados na sua mediação, e retorno ao imediato, mas integrados num todo significativo mais complexo, pelo que continuam a codeterminar os conteúdos posteriores. Seria impossível, neste estudo, um exame extensivo da exposição da Ciência da Lógica sob esta perspectiva. Os paralelismos entre diferentes esferas do sistema por um lado, e a possibilidade de retorno da imediatez como culminar de um processo de mediação, por outro, são constituintes essenciais do método e do sistema hegelianos. Segundo a figura dos paralelismos, cada esfera de realidade, conforme sistematizada na Filosofia da Natureza e do Espírito na Enciclopédia das Ciência Filosóficas corresponde a uma esfera de determinação lógica que permite conceptualizá-la de forma adequada. O retorno ao imediato, por outro lado, corresponde justamente à possibilidade de geração de conteúdo a partir da mediação. Todo o conteúdo determinado possui um momento de imediatez, pelo qual é conceptualizado como determinação autônoma do pensar ou da realidade.

\footnotetext{
$361830, \S 15$.

37 “[I]mmanente Deduktion” (1816, 12). Da perspectiva histórico-filosófica cf. Werke, 20, 390.

38 Acerca dos paralelismos entre as diferentes partes do sistema, v. V. Hösle, Hegels System. Der Idealismus der Subjektivität und das Problem der Intersubjektivität (Felix Meiner, Hamburg, 1988, $101 \mathrm{ss})$.

39 A "essência" será definida, num momento totalmente mediador e negativo como "movimento de nada para o nada e, assim, de volta a si mesma" ("Bewegung von nichts zu Nichts und dadurch zu sich selbst zurück") $(1813,14)$.

${ }^{40} \mathrm{O}$ movimento é característica geral de toda a dialética, o denominado "movimento do pensar". Mas o movimento, num sentido especial, é próprio do conceito, e a dialética, do pensar conceptual. O devir é próprio do conceito como o mais específico da filosofia hegeliana, a noção de "desenvolvimento", desconhecida dos outros níveis, pré-conceptuais da Lógica.
} 


\section{O conteúdo da lógica dialética}

Foi acima referido que o conteúdo lógico, que consiste em pensamentos objetivos, categorias, ou significações está, na sua generalidade, disponível na linguagem e na história da filosofia. No entanto, observou-se igualmente que a exigência conceptual da fundamentação requer que, a par desta fonte, que oferece os conteúdos empírica e historicamente, haja uma outra fonte para os mesmos conteúdos. As duas fontes devem confirmar-se, corrigir-se e completar-se uma à outra. Isto significa que é necessária uma história, uma cultura e uma linguagem suficientemente ricas e desenvolvidas para que a Lógica possa ser desenvolvida e o pensamento conceber e formular a sua própria fundamentação autônoma. A Fenomenologia do Espírito descreve todo um mundo filosófico, cultural, moral, religioso e espiritual como pressuposto para a "pura ciência" especulativa. E, novamente, a Filosofia do Espírito, terceira parte da exposição enciclopédica do sistema, expõe conceptualmente formas realizadas do espírito, subjetivo e objetivo, como sejam o desenvolvimento antropológico e educativo da consciência, as suas faculdades de conhecimento e ação, a família, o estado, a religião ou a arte como condições para a exposição da filosofia especulativa, no seu último capítulo. Mas tanto na Fenomenologia quanto na Filosofia do Espírito, esta exposição é, acima de tudo, conceptualizada segundo uma necessidade interna e não tomada sem mais da história ou da experiência.

A linguagem, a Filosofia do Espírito e a experiência histórica são condição real e, em parte, também condição ideal do desenvolvimento da Ciência da Lógica, mas, pelas razões acima apontadas, esta reivindica também uma razão conceptual não histórica e uma validade independente das condições conceptuais do espírito, segundo a descrição da Filosofia do Espírito, e reais, conforme existentes na história. A lógica tem uma gênese e condições históricas e reais, mas constitui, do mesmo modo, um domínio de pura validade, dir-se-ia puramente 'axiomático', na medida em que deve valer simplesmente sem pressupostos. Este domínio não deve estabelecer com as suas condições reais extra-filosóficas, e restantes condições ideais, descritas no sistema da filosofia, mais do que uma relação de paralelismo, de mútua confirmação e parcial condicionamento. Em qualquer caso, o paralelismo não significa, contudo, de modo 
nenhum um isolamento e incomunicabilidade entre as diferentes esferas do sistema, porquanto a lógica não constitui uma esfera transcendental isolada e constituída à parte da sua relação com as esferas paralelas - a natureza e o espírito. A sua autonomia não se exprime como isolamento formal perante uma materialidade empírica intuível, mas como capacidade de autodeterminação do próprio conteúdo.

Contudo, se a fonte histórica e empírica, não autônoma de conteúdos é conceptualizada por um pensar entendido como autônomo, deve levantar-se a questão acerca da origem do conteúdo no seu sentido estritamente lógico, que não pode ser tomado da experiência, da história e da linguagem. A questão que nos tem então de ocupar em seguida é então: senão da história da filosofia e da linguagem, de onde provém o conteúdo da lógica?

A questão poderá ser levantada nos dois níveis referidos da exposição, o nível classificativo e o nível dedutivo. Observe-se, em primeiro lugar, que a exigência de que forma e conteúdo não se distingam tem como consequência a reivindicação de que o conteúdo classificado não seja tomado de outra fonte senão a partir do próprio sistema classificativo. Assim, o conteúdo deve ser gerado pelo próprio lugar que ocupa na ordem classificativa. Neste contexto, dois pontos são de especial importância. (1) Todo o conteúdo deriva da diferença ou da negação. (2) Toda a diferença e, com ela, toda a relação está referida, em última instância, à negação. No entanto, a ordem classificativa, pela sua característica expositiva estática, de expor os conteúdos um ao lado do outro, não permite por si só aceder ao mecanismo conceptual pelo qual Hegel pretende gerar conteúdo significativo a partir dos meros lugares ocupados no sistema. O conteúdo gera-se em virtude do denominado "movimento do pensar", o que exige que a sua consideração passe de uma ordem diferencial de coexistência e subsistência, que encontra um paralelo exemplificativo na espacialidade (segundo os $\S \S 254-256$ da Enciclopédia), para uma ordem negativa e contraditória de refutação e exclusão, que encontra um paralelo exemplificativo na temporalidade (pura negatividade, conforme os $\S \S 257-259$ da Enciclopédia).

O conteúdo é gerado pela posição respectiva no sistema, pelo que este tem de ser entendido como sistema puramente diferencial ou 'topológico,41. O sistema

\footnotetext{
${ }^{41}$ Não teríamos aqui melhor comentário a fazer além de reproduzir as palavras do Cours de linguistique générale (Payot, Paris, 2005, 162) de Ferdinand de Saussure, segundo o qual "dans tous ces cas nous
} 
apresenta, nestas condições, diferenças estaticamente mas trata-se, na verdade, de um sistema de "diferenciação".

"Uma divisão filosófica não é, em geral, uma classificação exterior de um material disponível, feita segundo um qualquer, ou diversos fundamentos de divisão, mas o diferenciar-se imanente do próprio conceito" ${ }^{42}$.

Não há conteúdo além da relação ao outro, em particular, e ao sistema como um todo. Como autodiferenciação, a classificação dialética é análoga a uma classificação filogenética, onde a classe é definida pela origem. A apresentação da dialética segundo categorias biológicas, como se irá ver, justifica-se por esta ligação genética da diferenciação conceptual.

$\mathrm{Na}$ medida em que o modelo classificativo parece insuficiente para a compreensão mais aprofundada da gênese dos conteúdos lógicos, uma breve caracterização do processo de geração de conteúdo segundo a ordem linear e dedutiva de exposição do sistema lógico deverá preceder quaisquer outras considerações. Segundo esta ordem linear, cada categoria lógica deriva da imediatamente anterior. A condição essencial para que a exposição seja "científica" é a rigorosa imanência do seu desenvolvimento. Segundo se exige, nenhuma consideração ou reflexão exterior, ou posterior, i.e., ainda não derivada, deverá intervir constitutivamente na condução do processo. Poderá servir somente exteriormente ao desenvolvimento, a título ilustrativo ou comparativo.

surprenons donc, au lieu d'idées donnés d'avance, des valeurs émanant du système. Quando on dit qu'elles correspondent à des concepts, on sous-entend que ceux-ci sont purement différentiels, définis non pas positivement par leur contenu, mais négativement par leurs rapports avec les autres termes du système. Leur plus exacte charactéristique est d'être ce que les autres ne sont pas". Uma outra imagem sobre o modo como o "lugar" ocupado no sistema por um elemento determina o seu conteúdo qualitativo, de outro modo qualitativamente indeterminado, poderia tomar-se da neurobiologia. Também aqui, dada a "neutralidade do código neuronal", ou seja, que não há uma codificação específica para as diversas "modalidades (ouvir, ver)", nem para as diferentes "qualidades (cor, forma, na visão; altura, intensidade, na audição)", "kommt, wie bereits Helmholtz vermutete, das Prinzip des »Verarbeitungsortes« zum Tragen: Der Ort, an dem eine bestimmte Erregung verarbeitet wird, bestimmt seine Modalität und auch seine Qualität" (110) (G. Roth, Das Gehirn und seine Wirklichkeit. Kognitive Neurobiologie und ihre philosophischen Konsequenzen (Suhrkamp, Frankfurt a. M., 1998², pp. 93, 110).

42 "Eine philosophische Einteilung ist überhaupt nicht eine äußerliche, nach irgendeinem oder meheren aufgenommenen Einteilungsgründen gemachte äußere Klassifizierung eines vorhandenen Stoffes, sondern das immanente Unterscheiden des Begriffes selbst” (1820, §33A, 49). Cf. tb. 1816, 19. 
O processo dialético de geração de conteúdo pode ser caracterizado em três passos e uma condição. (1) Nas condições da representação ou da empiria, a negação de um determinado termo ou conceito não permite determinar nenhum conteúdo para um conceito. A este nível, a negação é indeterminada. Negar simplesmente um termo nada produz de determinado (e.g. branco/não-branco, i.e., nenhuma cor determinada). Na medida, porém, em que se procura definir um "espaço lógico" 43 da determinação o regime de determinação é diverso. Este espaço de determinação é entendido como bipartido, ou seja, a negação de um termo é igual à posição do termo oposto ${ }^{44}$. Parte-se, então, de uma definição, como um "imediato", ou seja, de um termo que é dado como único, despido de toda e qualquer referência a um outro. Exemplos na Lógica de Hegel poderiam ser o "puro ser", a "identidade abstrata" ou a "universalidade" sem mais ${ }^{45}$. Um tal termo, ao ser admitido como imediato, é o único a definir o "espaço lógico" da determinação. Ele é, nos termos de Hegel, uma "definição do absoluto"46, o que podemos entender como a definição ontológica de base ${ }^{47}$. No regime lógico, bipartido, de determinação, a negação é determinada, ou seja, suficiente para gerar um conteúdo determinado ${ }^{48}$. Assim, segundo os exemplos referidos o "ser", suposta a sua negação imanente, contém uma referência ao "não-ser", a "identidade" à "não-identidade" e o "universal” ao "não-universal”. Esta negação determinada dos termos imediatos referidos, não é somente algo de negativo em geral, mas um negativo que, de certo modo, vem completar a sua contraparte dita positiva. Nos exemplos, o oposto recebe

\footnotetext{
${ }^{43}$ Empregam esta noção a propósito da lógica de Hegel, L. B. Puntel, "Lässt sich der Begriff der Dialektik klären?" (in Journal for General Philosophy of Science, 27 (1996), 131-165, 142) e A. F. Koch, "Die Selbstbeziehung der Negation in Hegels Logik" (in Zeitschrift für philosophische Forschung, 53 (1999), 1-29, 10).

${ }^{44} \mathrm{Cf}$. Wandschneider, op.cit.

${ }^{45}$ Cf. 1832, 71; 1813, 27; 1816, 33.

${ }^{46}$ Cf. $1830, \S 85$.

${ }^{47}$ Este mecanismo poderia ser estudado na sua forte analogia com a dialética fichteana referida. Nesta, o denominado "espaço lógico" é definido por princípio como a subjetividade, ou "eu". Se, por um lado, parece introduzir um subjetivismo, rispidamente criticado por Hegel, por outro lado, ajuda a compreender como e porque "eu" e o seu oposto "não-eu" não podem subsistir lado a lado sem que se institua uma relação ativa entre eles, nomeadamente, ação ou conhecimento. É que ser um eu, ou ser sujeito implica sempre conhecer ou agir sobre o seu outro, e jamais admite um estar lado a lado indiferente das duas determinações ("eu" e "não-eu"). Uma só se constitui na sua referência e relação à outra - o que se compreende mais facilmente para um "eu" ou um ser vivo, dotados sempre de atividade de relação com o seu outro.

${ }^{48}$ Registe-se que, em termos de juízos, segundo Hegel, este termo de base é um predicado que vem determinar ou definir o sujeito, entendido como à partida totalmente indeterminado. Hegel insiste em que não temos aqui um sujeito "representado" como substrato dado (cf. 1807, 17, 46ss.). Trata-se, segundo a conhecida teoria da frase especulativa, na Fenomenologia, de um lugar vazio para a determinação. Este sujeito pode ser entendido como o "absoluto" ou o referido "espaço lógico" a ser definido pelo predicado em questão. Se se admitir em tese, com Hegel, que a definição deste predicado ou termo imediato é por sua vez contraditória, esta definição contém em si o predicado ou termo conceptual oposto.
} 
nomes positivamente definidos, e conteúdo linguisticamente acessível, designadamente, "nada", "diferença" ou "particular". Trata-se, em cada caso, de um retorno ao imediato, da autonomização da nova significação, como imediata, em relação às mediações anteriores que a produziram.

(2) No momento da negação, dispõe-se então de uma mediação, ou seja de uma dualidade de termos; nos casos referidos, dispõe-se então dos pares conceptuais ser/nada, identidade/diferença, universal/particular. (3) Cada termo isolado encerra uma referência ao outro, o que permite supor que há uma relação entre eles, que não está dita explicitamente nem em um, nem em outro, de tal modo que esta relação poderá ser explicitada como um novo conteúdo categorial. Nos nossos exemplos, a relação entre os dois é definida como "devir", "contradição" ou "singular".

Caracterizada assim a relação da imediatez à mediação e subsequente retorno ao imediato, como novo conteúdo, merece então atenção a condição admitida em tese de que o imediato é contraditório em si mesmo. A conhecida frase de Espinosa "omnis determinatio negatio est" é apresentada por Hegel como contendo o motivo da negação ou "contradição" interna que cabe a todo o termo conceptual determinado ${ }^{49}$. Nestes termos, qualquer tentativa de definição ou de determinação do espaço lógico inclui a potencialidade de uma duplicação ou desdobramento desse espaço por via daquilo que a definição implicitamente não afirma, ou nega. No regime de determinação lógica, "não afirmar" deve ser entendido ativamente como equivalente a "negar", qualquer determinação exclui e nega a oposta.

Esta situação, de simples negação, não parece prima facie conter nenhuma contradição, nem entre os dois opostos determinados, um perante o outro, e ainda menos de cada um em si mesmo. Deverá então examinar-se a razão e a justificação para a afirmação de Hegel de que todas as categorias ou determinações do pensar envolvem uma contradição, de tal modo que a "contradição" é o motor, a "alma" dialética do "movimento" lógico de determinação.

\footnotetext{
${ }^{49}$ Cf. $1832,107-108$.
} 
Não parece haver dúvida de que Hegel admite que as próprias coisas ou, em geral, "todo o finito" é contraditório, ou seja, que a contradição é uma determinação ontológica generalizada. Contradição não significa aqui a oposição entre juízos segundo a qualidade e a quantidade, mas designa uma oposição de exclusão entre termos, entre significados opostos ${ }^{50}$. Sobre a contradição, neste sentido, não se funda uma dialética de tipo socrático, onde frequentemente uma afirmação universal afirmativa, uma definição de um conceito é refutada pela apresentação de um contra-exemplo, um caso particular negativo que contradiz e invalida a definição. Contradição designa pelo contrário, em Hegel, uma incompatibilidade semântica entre termos opostos, ou seja, a relação vigente entre termos opostos que se excluem. Assim, a relação de contradição, que alegadamente constitui a existência autônoma do finito é de exclusão.

\footnotetext{
"Esta [autonomia do finito] consiste em conter em si a determinação que é sua outra e, assim, não ser somente referência a um exterior mas, do mesmo modo, em ser si mesmo e excluir de si a sua determinação negativa" ${ }^{, 51}$.
}

Nestes termos, Hegel admite que a relação de contradição é uma relação de exclusão entre os opostos contraditórios, podendo dizer-se que, neste sentido, Hegel admite a validade do princípio da não-contradição. A exposição de Hegel, no entanto, parece assumir que a contradição constitui o ente finito (a sua "autonomia", i.e., a sua substância) por exclusão do oposto desse mesmo ente, ou seja, daquilo que ele não é, ou das determinações que ele não possui. Mas qual a legitimidade e a razão por que Hegel designa "contradição" justamente aquilo que denominaríamos, aparentemente com maior justiça, justamente o seu oposto, ou seja, a "exclusão da contradição"?

Nesta relação de exclusão estão presentes um lado positivo e outro negativo e, por isso, "cada um é mediado consigo pelo seu outro e contém-no. Mas é, além disso, mediado consigo pelo não-ser do seu outro; então ele é unidade que é para si e exclui o

\footnotetext{
${ }^{50}$ V. C. Cirne-Lima, "Brief über die Dialektik", in D. Wandschneider (ed.), Das Problem der Dialektik, Bouvier, Bonn, 1997, 77-89, 83.

51 "Diese [Selbständigkeit] besteht darin, die ihr andere Bestimmung in sich zu enthalten und dadurch allein nicht Beziehung auf ein Äußerliches zu sein, aber ebensosehr unmittelbar darin, sie selbst zu sein und die ihr negative Bestimmung von sich auszuschließen" $(1813,51)$.
} 
outro de si" ${ }^{, 52}$. Negativo e positivo contêm cada um deles o outro na medida em que o excluem. Trata-se, por conseguinte de uma "relação negativa", ou seja, de exclusão. Considerada a questão a nível empírico, poderia tomar-se como exemplo, a proposição de que "este corpo estava, no dia 1 de Novembro de 1938, entre as 9:00h. e as 10:00h., com carga elétrica positiva" ${ }^{\text {. }}$. A contradição, no sentido pretendido por Hegel, significa somente que a negação desta proposição está incluída na determinação do seu significado, devendo somente ter-se em atenção, conforme se referiu, que não se trata de uma contradição entre juízos. Trata-se antes da inclusão do negativo na determinação positiva do conteúdo. Ou seja, do resultado, a este nível muito modesto no que se refere ao conteúdo acrescentado, de que "estar com carga elétrica positiva" envolve a negação da proposição: 'não estar ao mesmo tempo com carga elétrica positiva'. Ao nível da relação positivo/negativo que pertence, na verdade, a toda a determinação em geral, o negativo está incluído na definição do positivo, o que justifica a afirmação do caráter contraditório de toda a determinação. Esta inclusão, no entanto, é uma 'inclusão negativa' que na verdade não se distingue, da perspectiva positiva, da exclusão do oposto.

Isto significa que a contradição não é a destruição de todo o sentido determinado mas, pelo contrário, é-lhe constitutiva. Assim, segundo Hegel, "a contradição não tem só um resultado nulo", “ a contradição resolve-se" ${ }^{\text {"54 }}$. Uma vez que se trata, antes de mais, de que a afirmação da autonomia substancial de qualquer determinação envolve a exclusão da determinação oposta, o uso do termo "contradição" por Hegel não é plenamente justificado, ou pelo menos não coincide com o uso comum do termo. Ao afirmar que "todas as coisas são contraditórias em si mesmas",55, Hegel não está a defender que o princípio da não-contradição não é válido no seu sentido usual. Assim, no exemplo citado, Hegel não está a dizer que “um corpo está e não está

\footnotetext{
52 "“...] ist jedes vermittelt durch sein Anderes mit sich und enthält dasselbe. Abe es ist ferner durch das Nichtsein seines Anderen vermittelt; so ist es für sich seiende Einheit und schließt das Andere aus sich aus" $(1813,50)$.

${ }^{53} \mathrm{O}$ exemplo é tomado de K. Popper (Conjectures and Refutations. The Growth of Scientific Knowledge, Routledge and Kegan Paul, London, 1985, 329): "An example of a true contradiction would be two sentences: 'this body here was, on the 1st of November, 1938, between 9 and 10 a.m., positively charged', and an analogous sentence about the same body, saying that it was at the same time not positively charged". Não será necessário esclarecer que embora retire o exemplo de K. Popper, considero que a sua formulação de uma "true contradiction" não corresponde à contradição em sentido hegeliano. 54 “[D]as Resultat des Widespruchs ist nicht nur Null” $(1813,53)$, "Der Widerspruch löst sich auf” (1813, 52)

55 "Alle Dinge sind an sich selbst widersprechend" $(1813,59)$.
} 
ao mesmo tempo com carga elétrica positiva" mas, conforme se referiu, a afirmar que a determinação "estar com carga elétrica no tempo t" inclui a negação de "não estar com carga elétrica no tempo t" - afirmação que, a este nível nada tem de contraditório e bastante se aproxima aliás do senso comum. Só a partir do momento em que se reflete acerca do significado do positivo e do negativo em abstrato, conforme presente nestas determinações, é que se pode falar em contradição. Assim, o positivo envolve o negativo, sob a forma da negação do negativo - ou seja, de certo modo, justamente o negativo, cuja presença é, dado seu significado próprio, uma presença negativa ${ }^{56}$.

O pensamento dialético baseia-se numa permanente reafirmação da negação como relação, de tal modo que, por assim dizer, não é pensável uma não-relação ou exclusão da relação simplesmente, mas a negação da relação deve ser entendida sempre como relação negativa. Compreende-se, assim, que o sistema das determinações é decisivo para o pensamento dialético. A dialética serve-se sempre de uma "unidade negativa" 57 ou negatividade que une.

\section{O conceito da dialética lógica}

Se refletirmos agora acerca do modo como a dialética tem sido definida pela nossa pesquisa até aqui, ou seja, dos conceitos a partir dos quais a definimos, encontraremos três modelos principais, além de modelos menos bem definidos que gravitam em torno dos principais.

Em primeiro lugar, o modelo categorial mais frequentemente admitido e estudado do desenvolvimento dialético: a contradição conceptual como exclusão do oposto, conforme analisamos acima. Este modelo centra-se no conceito da contradição, localizado no início da Lógica da Essência.

Em segundo lugar, um modelo igualmente privilegiado por Hegel, mas que é porventura tomado como não mais do que uma exposição metafórica: a dialética como

\footnotetext{
${ }^{56}$ Que este gênero de reflexões, aparentemente sofístico, uma vez formulada em termo de antinomias, pode ter resultados filosoficamente interesssantes é o que se constata em obras como, por exemplo, Th. Kesselring, Die Produktivität der Antinomie. Hegels Dialektik im Lichte der genetischen Erkenntnistheorie und der formalen Logik (Suhrkamp, Frankfurt a. M., 1984), ou Wandschneider, op.cit. $571813,63$.
} 
vida do conceito ou "alma dialética". Assim, "esta dialética [superior] não é, então, um agir exterior de um pensar subjetivo, mas a própria alma do conteúdo, que produz organicamente os seus ramos e frutos" ${ }^{~} 58$. Para além da exposição classificativa em árvore, conforme já estudado acima, encontramos a dialética apresentada como vida do pensar. Este modelo encontra o seu topos lógico no final da Lógica do Conceito, com a “ideia de vida". Segundo a compreendemos, não se trata de uma metáfora, mas somente de uma conceptualização a um nível mais complexo e concreto, o da ideia de vida. O pensar é, literalmente, uma função vital.

Em terceiro lugar, refira-se um modelo menos frequente, mas igualmente atestável no texto hegeliano: a particularização do universal. Ainda na mesma anotação das Linhas Fundamentais da Filosofia do Direito lê-se que "chamo dialética ao princípio motor do conceito, que não só dissolve como também produz as particularizações do universal" $"$. Ou então, na Ciência da Lógica, "o conceito do método absoluto mantém-se no seu ser-outro, o universal na sua particularização, no juízo e na realidade" ${ }^{, 60}$. A relação entre universal, particular e singular encontra-se tematizado, como determinação do pensar, no começo da Lógica do Conceito.

Poderá referir-se ainda, como modelos menos frequentes ou menos claramente caracterizados, uma compreensão do método como método "silogístico", que poderá ser entendido somente como uma explicitação das relações entre universal, particular e singular. A silogística é, sem dúvida, a base da forma expositiva de que Hegel se serve em especial nos momentos mais complexos da exposição, com particular relevância para os momentos finais tanto da Ciência da Lógica quanto da Enciclopédia. A silogística dá a forma geral, por exemplo, da "ideia prática" ou da ideia da religião ou da filosofia ${ }^{61}$.

\footnotetext{
58 "Diese [höhere] Dialektik ist dann nicht äußeres Tun eines subjektiven Denkens, sondern die eigene Seele des Inhalts, die organisch ihre Zweige und Früchte hervortreibt" (1820, § 31). Cf. tb. 1816, 290, 296-297. Tb. 1820, § $81 \mathrm{Z}$.

59 "Das bewegende Prinzip des Begriffs, als die Besonderungen des Allgemeinen nicht nur auflösend, sondern auch hervorbringend, heiße ich Dialektik" $(1820, \S 31)$.

60 "Der Begriff in der absoluten Methode erhält sich in seinem Anderssein, das Allgemeine in seiner Besonderung, in dem Urteil und der Realität" (1816, 302). Cf. tb. 1816, 294, 299.

${ }^{61}$ Cf. e.g. 1816,279 ss; 1830 , $\S \S 571$ e 575 ss. Sobre esta forma de exposição do método, v. ainda K. Düsing, "Syllogistik und Dialektik in Hegels Wissenschaft der Logik", in D. Henrich (ed.), Hegels Wissenschaft der Logik. Formation und Rekonstruktion, Klett-Cotta, Stuttgart, 1986, pp. 15-38.
} 
Refira-se ainda a utilização insistente, na caracterização da dialética, da categoria do "outro", ou da "alteridade", em especial no capítulo final da Ciência da Lógica, sobre a "ideia absoluta". "Deve denominar-se o momento dialético este momento tanto sintético quanto analítico do juízo, pelo qual o universal inicial se determina, a partir de si próprio, como o outro de si ${ }^{, 62}$. A alteridade tem o seu lugar categorial logo no início da Lógica do Ser, e consiste na forma mais geral, porque mais elementar, da diferença.

Hegel serve-se de cada uma destas categorias ou determinações do pensar como um centro para a definição da dialética e frequentemente as cruza, servindo-se ainda de outras determinações lógicas, como necessidade, essência, devir, etc. Todos os modelos principais e secundários assim referidos - (a) a contradição, (b) a ideia de vida, (c) a relação entre universal e particular, (d) a silogística ou (e) a alteridade - são outras tantas categorias expressamente derivadas, classificadas e definidas na Ciência da Lógica, nos locais apontados. Esta expõe, por conseguinte, claramente, e deduz, segundo os seus princípios, o seu próprio método.

Não parece haver qualquer motivo especial para a seleção e privilégio destas determinações do pensar, que parecem, pelo contrário, encontrar-se dispersas pela obra sem nada que em especial as habilite para desempenhar as funções metodológicas generalizadas a que são chamadas. Deverá questionar-se a razão por que Hegel conceptualiza a dialética a partir destas diversas categorias, se há alguma chave, a encontrar necessariamente dentro da própria lógica, para esta seleção.

As caracterizações elencadas da dialética, embora não devam certamente ser incompatíveis entre si, tão-pouco são apresentadas como necessariamente complementares, sendo utilizadas ora em conjunto, ora separadamente. Ou seja, os conceitos referidos, de (a) a (e), parecem fundar caracterizações até certo ponto alternativas do método. Cada um apresenta uma definição geral suficiente do método. $\mathrm{O}$ método tanto pode ser definido a partir da noção de contradição, quanto de vida, de particularização ou de alteridade. Mas se entendermos a totalidade da Ciência da Lógica como movimento dialético e especulativo do pensar, teremos de concluir que não existe a chave buscada para saber a razão da seleção destas determinações particulares para

\footnotetext{
62 "Dieses sosehr syntetische als analytische Moment des Urteils, wodurch das anfängliche Allgemeine
} aus ihm selbst, als das Andere seiner sich bestimmt, ist das Dialektische zu nennen" (1816, 291 e passim). 
pensar e expor o método. E, se assim é, poderá dizer-se que se trata somente de opções expositivas de Hegel. Ou seja, por princípio, todas as outras determinações estariam igualmente aptas, em condições alternativas da exposição, para a exposição do método. Este é o significado da afirmação já citada de Hegel, de que é o próprio "método que se amplia em sistema". Método e sistema não se distinguem, porquanto os conteúdos sistemáticos são gerados a partir das determinações do método, conforme se estudou acima, e toda a lógica é então uma teoria do seu próprio método em cada uma das suas transição particulares. Trata-se de uma consequência necessária do fato de não haver uma teoria do método ainda mais geral, ou metateoria explicativa dos procedimentos dialéticos da Ciência da Lógica.

\section{Conclusões e perspectivas}

Não seria adequado avançar aqui mais além no difícil caminho de um pensar que pretende ao mesmo tempo autofundamentar-se e estabelecer uma relação dialéticoespeculativa com o seu outro, i.e., com o real. A autonomia lógica, reivindicada como autodesenvolvimento necessário e possibilidade de começar sem pressupostos, não é a autarcia totalmente implausível de um pensar que se limita a deduzir-se circularmente a si mesmo em simples autoconservação, reivindicando ainda, além disso, a partir do seu próprio vazio, poder determinar a realidade. É manifesta a inadequação de qualquer interpretação que compreenda a Ciência da Lógica como uma tal teoria.

Se o percurso realizado sobre o seu método é correto, pode concluir-se que a lógica dialética define, em todos os seus momentos, o seu próprio método como referência ao seu outro ou seja, não só a sequência de determinações que expõe, e o seu próprio sistema lógico, mas define também o restante sistema da filosofia. Na medida em que a lógica é autônoma, ou seja, em que não deve receber o seu conteúdo de nenhuma outra ciência, cada momento categorial nela derivado e determinado consiste, em geral, no conjunto de diferenças que estabelece com os outros momentos. Em particular, cada momento da lógica se deve deixar definir por todos os outros, ou seja, cada uma das categorias expõe, de uma perspectiva particular, o conteúdo conceptual de todo o sistema lógico das determinações. Sendo o conteúdo eminentemente relacional, diferencial, negativo, i.e., dialético, em cada um dos momentos da lógica encontramos 
uma exposição parcial do todo relacional, diferencial, negativo e dialético da Ciência da Lógica. As relações lógicas expõem e permitem pensar, a todos os níveis, as relações diferenciais, negativas e dialéticas da lógica com o seu outro, o restante sistema da filosofia, a própria realidade natural e espiritual.

Retomando as questões iniciais, poderemos concluir que o método praticado por Hegel, contrariamente a uma concepção técnica do método, não consiste num instrumento pelo qual se economiza, por simples reaplicação, o trabalho do conceber a cada passo realizado efetivamente. Assim, o método não é, de modo nenhum comparável a uma instrumento formal que se possa aplicar a um conteúdo diverso. Nesta medida, muito dificilmente se poderia vislumbrar alguma perspectiva ou utilidade numa tentativa de formalização do método. No entanto, o método hegeliano, conforme tematizado e efetivado na Ciência da Lógica é suficientemente regular, e produz procedimento e resultados suficientemente regulares para que não possa ser entendido simplesmente como uma arte subjetiva insusceptível de uma caracterização geral. Existem claramente diferenças de concepção do método ao longo do seu desenvolvimento histórico-conceptual, podendo detectar-se imperfeições que comprometem o seu significado anteriormente à forma assumida na Ciência da Lógica. Por outro lado, as diferenças de caracterização do método na obra da maturidade parecem derivar antes da própria natureza da exposição e do empreendimento sistemático, sendo tais diferenças reconduzíveis a uma unidade de sentido conceptual. Esta unidade é o núcleo especulativo do pensar que se expõe, segundo Hegel, como sistema lógico-dialético de determinações do pensar. 